Original article

Central Eur J Paed 2018;14(1):73-80

DOI $10.5457 / \mathrm{p} 2005-114.202$

\title{
The incidence of glucose dysregulation in children with metabolic syndrome
}

\author{
Ivana Vorgucin, Dragan Katanic \\ Faculty of Medicine, University of Novi Sad Objective - The aim of the research was to establish the incidence \\ Institute for Child and Youth Health Care of increased fasting glucose concentration and insulin resistance/in- \\ of Vojvodina, Novi Sad, Serbia \\ Correspondence: \\ ivana.vorgucin@mf.uns.ac.rs \\ Tel.: + 38638688583 \\ Fax.: + 38121420452 \\ Received: January 2, 2018 \\ Accepted: February 12, 2018 \\ creased insulin levels within the scope of metabolic syndrome (MS) in \\ overweight and obese children and adolescents. Materials and meth- \\ ods - Two sets of criteria for diagnosing MS were applied to the whole \\ sample $(n=206)$ : the criteria for adults, specifically adapted for chil- \\ dren, and the criteria of the International Diabetes Federation for chil- \\ dren and adolescents. Fasting plasma glucose (FPG) and insulinaemia \\ were analysed in the first and second hour of the oral glucose tolerance \\ test (OGTT) and homeostatic model assessment of insulin resistance \\ (HOMA IR). Results - Increased FPG was registered in just $8.8 \%$ of \\ the adolescents with MS, while in $90 \%$ of cases, insulin resistance/ \\ increased insulin levels. FPG did not differ significantly in adolescents \\ with the MS diagnosed using both definitions, while the insulinaemia \\ values in the first and second hour of the OGTT and HOMA IR \\ were significantly higher in the patient with the MS diagnosed using \\ both definitions $(\mathrm{P}<0.01)$. Conclusion - A significant percentage of \\ glucose dysregulation in children with MS was established. \\ Key words: Children - Glucose • \\ Insulinaemia - Metabolic syndrome • \\ Obesity.
}

\section{Introduction}

Metabolic syndrome (MS) is a clinical term encompassing obesity, insulin resistance, dyslipidaemia and hypertension, as well as an increased risk of developing diabetes mellitus type 2 , early atherosclerosis, and cerebrovascular and cardiovascular diseases in early adulthood. The prevalence of MS is increasing and is directly related to the degree of obesity in children. In 1988, Gerald M. Reaven (1) described syndrome X and highlighted the importance of insulin resistance for the onset of atherosclerosis and the connection of this disorder with obesity, dyslipidaemia and the onset of diabetes. The current definition of MS in adults was suggested by a consensus of experts from the International
Diabetes Federation (IDF) in 2005 (2), while for children and adolescents the definition was adopted in 2007 (3). In many studies the diagnosis of MS in children was set using the criteria for adults, which were specifically adapted and modified to suit the child population. It was shown that using the specific criteria for children led to a diagnosis of MS in children much more frequently (4-10).

The complexity of the pathogenesis of MS is conditioned by the existence of numerous metabolic and non-metabolic components which have causal and additional effects. The central characteristics of the MS are visceral obesity, glucose dysregulation, accompanied by dyslipidaemia (low HDL cholesterol, elevated triglycerides) and elevated blood pressure. Earlier definitions saw insulin resistance 
as the primary cause of MS, where insulin resistance was the main criterion for diagnosing MS $(11,12)$. Insulin resistance and/ or elevated insulin levels are the foundations of other components of MS. Obesity leads to increased secretion of insulin, while the presence of normal fasting plasma glucose levels with hyperinsulinism indicates insulin resistance. Obesity, through insulin resistance, leads to the exhaustion of the endogenous pancreas and contributes to the onset of diabetes mellitus. Over the past several years there has been much discussion about whether hyperinsulinaemia precedes insulin resistance or is insulin resistance primary. The great proneness of abdominal, especially visceral, fat tissue to lipolysis leads to excess quantities of free fat acids being transported to the liver and muscles, where the liver's production of glucose is stimulated and hyperglicaemia worsens. The impossibility of lipolysis suppression in fat tissue is listed as an early manifestation of insulin resistance. On the other hand, increased release of free fat acids from adipocytes and increased synthesis of triglycerides in the liver are the foundation for the development of lipid disorders in the MS. The activities of adipocytes and chronic inflammation also have a strong effect on the onset of insulin resistance (13).

Confirming insulin resistance is not simple in clinical work, so more recent definitions emphasise the waist circumference as an independent predictor of insulin resistance, and lipid and blood pressure levels. It has been confirmed that increased waist circumference lowers insulin sensitivity and increases insulin levels (14). In the definition of MS in children and adolescents suggested by the International Diabetes Foundation, the entry criterion for carbohydrate metabolism disorder is fasting plasma glucose $\geq 5.6 \mathrm{mmol} / \mathrm{l}$, while other previous definitions suggested a more detailed examination of the carbohydrate metabolism.
The aim of the research was to establish the incidence of increased fasting glucose concentration and insulin resistance/increased insulin levels within the scope of MS in overweight and obese children and adolescents.

\section{Methods}

The research was conducted as a cross study analysis of children and adolescents under 18 years of age, treated and controlled for overweight and obesity at the Department of Endocrinology, Diabetes and Metabolism Disorders and the Endocrinology Clinic of the Institute for Child and Youth Health Care of Vojvodina in Novi Sad between 2004 and 2008. The sample comprised 206 patients, divided into two groups, depending on the body mass index (BMI): overweight patients (BMI 85-95 percentiles) and obese patients (BMI over 95 percentiles). Each group was further divided according to age: children up to 10 years of age (including those aged 10) and adolescents.

The following values were recorded for all patients: BMI, waist circumference, pubertal status, arterial pressure, triglycerides, $\mathrm{HDL}$ cholesterol, glucose and insulinaemia during the oral glucose tolerance test OGTT. Two sets of criteria for diagnosing the MS were applied: the criteria for adults, specifically adapted for children, and the criteria defined by the IDF for children and adolescents. The physical examinations included the following: measuring body weight, height using a Harpenden stadiometer, waist circumference (WC) in centimetres using a non-elastic tape at the navel level and BMI defined as the individual's body weight divided by the square of his or her height in meters $\left(\mathrm{kg} / \mathrm{m}^{2}\right)$. The arterial pressure was measured with a standard auscultation sphygmomanometer, using a mercury manometer and the cuff length for blood pressure measurement was chosen as 
$2 / 3$ length of the upper arm. Children were asked to sit for at least $5 \mathrm{~min}$ before measurement. Two recordings were taken, with a 2 min interval in between, the average of the two measurements was used for statistical analysis. The results obtained were compared against the nomograms (15), and the entry criterion for diagnosing the MS was the existence of supra-normal pressure - systolic, diastolic or both.

Laboratory analysis of triglycerides and HDL cholesterol within the lipid status was conducted using an enzyme colorimetric test method (Roche/Hitachi 902 analyser) after the patients had been deprived of food for 12 hours. The standard 2-hour OGTT was conducted after the patients had been deprived of food for 12 hours with $1.75 \mathrm{~g} / \mathrm{kg}$ glucose orally (maximum $75 \mathrm{~g}$ ). Venous blood samples for plasma glycaemia and insulinaemia analysis were taken every 30 minutes over 120 minutes of the test. The laboratory analysis of glycaemia was conducted using the hexokinase method (Roche/Hitachi 902 analyser), while the analysis of insulinaemia was conducted using the immunometric method (ADIVA Centaur XP analyser). The glycaemia values during the OGTT were analysed using the criteria of the America Diabetes Association (16). Fasting plasma glucose disorder is defined as values $\geq 5.6 \mathrm{mmol} / \mathrm{l}$, but $<7 \mathrm{mmol} / \mathrm{l}$; glucose tolerance disorder is defined as having values between 7.8 and 11 $\mathrm{mmol} / \mathrm{l}$ in the $2^{\text {nd }}$ hour of the OGTT; diabetes is defined as fasting plasma glucose values $\geq 7 \mathrm{mmol} / \mathrm{l}$ or $\geq 11.1 \mathrm{mmol} / \mathrm{l}$ in $2^{\text {nd }}$ hour of the OGTT. The insulinaemia values were assessed basally, in the first and second hour of the OGTT (17). The homeostatic model assessment was used to quantify insulin resistance (HOMAIR): insulin $(\mathrm{mU} / \mathrm{l}) \times$ fasting plasma glucose $(\mathrm{mmol} / \mathrm{l}) / 22.5$ (18).

A control group was not established, since there are nomograms for all patients, related to sex and age, determined using a large sample of children. The following nomograms were used: body mass index (19), waist circumference (20), blood pressure (15), HDL cholesterol and triglyceride values (21).The criteria for diagnosing MS in adults, specifically adapted for children, were applied $(22,23)$. MS is diagnosed if three or more of the following are present: BMI $>97$ percentiles for sex/age, arterial pressure $>95$ percentiles for sex/age, serum triglycerides $>95$ percentiles for sex/age, HDL cholesterol $<5$ percentiles for sex/age, pathological result of the OGTT (dichotomously defined: positive/negative). Based on the OGTT results, the entry criteria for a pathological result, i.e. glycose dysregulation, were hyperglycaemia, glucose tolerance disorder, hyperinsulinemia, insulin resistance or diabetes.

Another set of criteria (3) were also applied for diagnosing MS - those prescribed by the IDF. In children aged 10-16, MS is diagnosed if the waist circumference is $\geq 90$ percentile (or applying the criteria for adults, if they are more strict), accompanied by two or more of the following parameters: triglycerides $\geq 1.7 \mathrm{mmol} / \mathrm{l}$, HDL cholesterol $<1.03$ $\mathrm{mmol} / \mathrm{l}$, elevated arterial pressure (systolic $\geq 130 \mathrm{mmHg}$, diastolic $\geq 85 \mathrm{mmHg}$ ), fasting plasma glucose $\geq 5.6 \mathrm{mmol} / \mathrm{l}$. MS was not diagnosed in children under 10 and additional tests were conducted only in the case of a positive family medical history. In case of children over 16 , the criteria for adults were applied.

\section{Ethics statement}

The parents and children had been informed about the nature and rationale behind the research and had signed an informed consent form for the relevant data to be included in the research. The ethical committee of the Institute for Child and Youth Health Care of Vojvodina, Novi Sad, Serbia had also given its approval for the research before it commenced. 


\section{Statistical analyses}

Appropriate statistical data processing was conducted after the research. Attributive (binary) and numerical variables were analysed using the standard procedures of descriptive statistics. Descriptive statistical methods were used to determine the central tendency (the mean) and dispersion (standard deviation) with numerical values (age), and frequency and relative relations (percentage) with attributive values. Comparative statistical methods were then used to compare certain pairs of traits, encompassing a t-test of two independent samples to test the difference between the mean values of certain pairs of numeric values, the $\mathrm{z}$-test for establishing the difference between the ratios of certain pairs of attributive values, and the Pearson correlation coefficient to measure the correlation between two numeric variables. In all the tests applied, the results with a significance level of $95 \%(\mathrm{P}<0.05)$ were interpreted as statistically significant.

\section{Results}

Among the 206 children included in the research, the BMI suggested that 153 of them (74\%) were obese and 53 (26\%) overweight. There were $155(75 \%)$ adolescents and 51
(25\%) children. The sample comprised (50.5\%) boys and 102 (49.5\%) girls, with an average age of $12.06 \pm 3.42$. Among the adolescents, $30.3 \%$ (47) were overweight and $69.7 \%$ (108) obese, while among the children there were $11.7 \%$ (6) overweight and $88.2 \%$ (45) obese. In the whole sample the parameters were analyzed for diagnosing MS in overweight and obese children and adolescents (Table 1).

When applying the specific criteria for diagnosing MS in children and adolescents to the whole sample, MS was diagnosed in 38\% of the patients, i.e. $9 \%$ of the overweight, $48 \%$ of the obese, $29 \%$ of the children and $41 \%$ of the adolescents. By applying the criteria from the definition of the International Diabetes Federation for children and adolescents, MS was diagnosed in $17 \%$ of the patients, that is, in $4 \%$ of the overweight, $22 \%$ of the obese and $22 \%$ of adolescents (the criteria were not applied to children under 10).

Furthermore, the carbohydrate metabolism of all patients, overweight, and obese children and adolescents, was carefully examined. Fasting plasma glucose and insulinaemia ( $1^{\text {st }}$ and $\left.2^{\text {nd }} h\right)$ were recorded during the OGTT and HOMA IR (Table 2).

The statistical t-test for two independent samples was used to determine the difference between fasting plasma glucose, insulinae-

\begin{tabular}{|c|c|c|c|c|}
\hline \multirow{4}{*}{ Parameters } & \multicolumn{4}{|l|}{ Subjects } \\
\hline & \multicolumn{2}{|c|}{ Children* $^{*}(\mathrm{n}=51)$} & \multicolumn{2}{|c|}{ Adolescents $\dagger(\mathrm{n}=155)$} \\
\hline & OW $(n=6)$ & $O(n=45)$ & $\mathrm{OW}(\mathrm{n}=47)$ & $\mathrm{O}(\mathrm{n}=108)$ \\
\hline & $\bar{x}_{ \pm S D}$ & $\bar{x}_{ \pm S D}$ & $\bar{x}_{ \pm} \mathrm{SD}$ & $\bar{x}_{ \pm} \mathrm{SD}$ \\
\hline BMI $(\mathrm{kg} / \mathrm{m} 2)$ & $20.52 \pm 0.43$ & $25.87 \pm 4.14$ & $28.54 \pm 4.78$ & $30.49 \pm 6.02$ \\
\hline WC (cm) & $65.25 \pm 9.35$ & $77.28 \pm 10.65$ & $85.3 \pm 10.34$ & $93.10 \pm 15.33$ \\
\hline BP (\%) & $6.1 / 0$ & $43.2 / 19.3$ & $8.4 / 2.5$ & $47.1 / 19.4$ \\
\hline TG $(\mathrm{mmol} / \mathrm{l})$ & $1.02 \pm 0.25$ & $1.05 \pm 0.31$ & $1.12 \pm 0.44$ & $1.29 \pm 0.55$ \\
\hline HDL-C $(\mathrm{mmol} / \mathrm{l})$ & $1.31 \pm 0.16$ & $1.28 \pm 0.18$ & $1.21 \pm 0.34$ & $1.19 \pm 0.23$ \\
\hline
\end{tabular}

${ }^{*}$ Children up to 10 years of age (including those aged 10 ); $†$ Adolescents from 11 to 18 years; OW=Overweight; O=Obese; $\mathrm{BMI}=$ Body mass index; WC=Waist circumference; $\mathrm{BP}=$ Blood pressure $>95 \mathrm{p} / \geq 130 / 85 \mathrm{mmHg}$; TG=Triglycerides; HDL-C=Highdensity lipoprotein cholesterol. 
Table 2. The average values of fasting plasma glucose and insulinaemia during OGTT and HOMA IR

\begin{tabular}{|c|c|c|c|c|}
\hline \multirow{4}{*}{ Parameters } & \multicolumn{4}{|l|}{ Subjects } \\
\hline & \multicolumn{2}{|c|}{ Children* $^{*}(\mathrm{n}=51)$} & \multicolumn{2}{|c|}{ Adolescents $\dagger(\mathrm{n}=155)$} \\
\hline & OW $(n=6)$ & $O(n=45)$ & OW $(n=47)$ & $\mathrm{O}(\mathrm{n}=108)$ \\
\hline & $\bar{x}_{ \pm} S D$ & $\bar{x}_{ \pm} S D$ & $\bar{x}_{ \pm} S D$ & $\bar{x}_{ \pm} S D$ \\
\hline $\mathrm{FPG}(\mathrm{mmol} / \mathrm{L})$ & $4.52 \pm 0.46$ & $4.55 \pm 0.47$ & $4.54 \pm 0.53$ & $4.62 \pm 0.47$ \\
\hline Insulin $1^{\text {st }} \mathrm{hr}(\mathrm{mUI} / \mathrm{ml})$ & $74.75 \pm 37.75$ & $95.31 \pm 37.45$ & $76.3 \pm 33.44$ & $97.4 \pm 51.23$ \\
\hline Insulin $2^{\text {nd }} \mathrm{hr}(\mathrm{mUI} / \mathrm{ml})$ & $56.69 \pm 36.53$ & $72.34 \pm 42.53$ & $59.38 \pm 34.66$ & $78.4 \pm 69.28$ \\
\hline HOMA IR & $1.96 \pm 1.52$ & $2.1 \pm 1.04$ & $2.23 \pm 1.12$ & $2.84 \pm 1.56$ \\
\hline
\end{tabular}

*Children up to 10 years of age (including those aged 10); †Adolescents from 11 to 18 years; OW=Overweight; O=Obese; FPG=Fasting plasma glucose; HOMA IR=Homeostatic model assessment of insulin resistance.

Table 3. T- test for independent samples, fasting plasma glucose, insulinaemia in $1^{\text {st }}$ and $2^{\text {nd }}$ hours of the OGTT, HOMA IR and MS diagnosed using the International Diabetes Federation definition.

\begin{tabular}{|c|c|c|c|c|}
\hline \multirow{2}{*}{ Parameters } & \multicolumn{2}{|l|}{ Subjects } & \multirow{2}{*}{ t value } & \multirow{2}{*}{$\mathrm{P}$ value } \\
\hline & $\operatorname{MS}(n=39 ; \bar{x} \pm S D)$ & No MS $\left(n=116 ; \bar{x}_{ \pm} S D\right)$ & & \\
\hline $\mathrm{FPG}(\mathrm{mmol} / \mathrm{l})$ & $4.7354 \pm 0.51$ & $4.5916 \pm 0.33$ & 1.63 & 0.103 \\
\hline Insulin $1^{\text {sthr }}(\mathrm{mUI} / \mathrm{ml})$ & $135.1551 \pm 35.55$ & $81.5185 \pm 32.66$ & 6.67 & 0.000 \\
\hline Insulin $2^{\text {nd }} \mathrm{hr}(\mathrm{mUI} / \mathrm{ml})$ & $117.2317 \pm 37.53$ & $62.0744 \pm 31.47$ & 5.11 & 0.000 \\
\hline HOMA IR & $4.3540 \pm 1.14$ & $2.1130 \pm 1.11$ & 8.58 & 0.000 \\
\hline
\end{tabular}

MS=Metabolic syndrome; FPG=Fasting plasma glucose; HOMA IR=Homeostatic model assessment of insulin resistance.

Table 4. T-test of the degree of obesity and insulinaemia in the first and second hours of the OGTT

\begin{tabular}{lllll}
\hline Parameters & $\mathrm{OW}(\mathrm{n}=53 ; \overline{\mathrm{x}} \pm \mathrm{SD})$ & $\mathrm{O}(\mathrm{n}=153 ; \overline{\mathrm{x}} \pm \mathrm{SD})$ & $\mathrm{t}$ value & $\mathrm{P}$ value \\
\hline Insulin $1^{\text {sth }}(\mathrm{mUI} / \mathrm{ml})$ & $85.31 \pm 34.25$ & $92.48 \pm 42.62$ & 0.94 & 0.350 \\
Insulin $2^{\mathrm{nd}} \mathrm{hr}(\mathrm{mUI} / \mathrm{ml})$ & $55.28 \pm 38.55$ & $77.04 \pm 33.25$ & 2.23 & 0.027 \\
\hline
\end{tabular}

OW=Overweight; $\mathrm{O}=$ Obese.

mia in the $1^{\text {st }}$ and $2^{\text {nd }}$ hours of the OGTT, HOMA IR, and MS in adolescents diagnosed using the specific criteria for children and adolescents, and the criteria stemming from the International Diabetes Federation definition (Table 3). Fasting plasma glucose did not show a statistically significant difference in adolescents with MS diagnosed using the two definitions, while the insulinaemia values in the first and second hours of the OGTT and HOMA IR ( $t$ value $6.67,5.11,8.58$ ) produced a statistically significant difference in adolescents with MS diagnosed using the two definitions $(\mathrm{P}<0.01)$. The correlation between the insu- lin in the first and insulin in the second hour of the OGTT was examined in all patients. A significant correlation $(\mathrm{P}<0.01)$ between the insulin values in the first and second hours of the OGTT was determined using the Pearson coefficient $(\mathrm{R}=0.77)$.

The statistical t-test for two independent samples was used to determine the difference between the degree of obesity and insulinaemia in the first and second hours of the OGTT (Table 4). There was no statistically significant difference between the insulin values in the first hour in the overweight and obese patients ( $t$ value 0.94 ), but the insu- 
lin values in the second hour ( $t$ value 2.23 ) were significantly higher in the obese patients $(\mathrm{P}<0.05)$.

In the group of adolescents diagnosed with the MS, a pathological result of the OGTT was recorded in $90 \%$ of the cases, while elevated fasting plasma glucose was registered in just $8.8 \%$ of the adolescents. A pathological result of the OGTT includes carbohydrate metabolism, i.e. hyperglycaemia, glucose tolerance disorder, hyperinsulinemia, insulin resistance or diabetes curve (dichotomy applied: positive/negative results).The test of the difference in presence of the pathologi$\mathrm{cal}$ result of the OGTT and increased fasting plasma glucose in adolescents with the MS was tested using the difference in proportions test and the result was that the pathological result of the OGTT was a significantly more present factor than increased fasting plasma $(\mathrm{P}<0.01)$.

\section{Discussion}

In this study, the results showed a significantly higher prevalence of obesity in children, and we have presented the results separately for children and adolescents. In the subsample of adolescents with MS, the existence of carbohydrate metabolism disorder and significantly more pathological results of the OGTT were noticed, despite maintaining regular fasting plasma glucose values. A detailed examination of the carbohydrate metabolism showed that there were carbohydrate metabolism disorders (hyperglycaemia, glucose tolerance disorder, hyperinsulinism, insulin resistance, subnormal insulin response, and diabetes) with normal values of fasting plasma glucose. The fasting plasma glucose values proved to be an unreliable criterion for carbohydrate metabolism disorder within the definition of MS. Since our results provided evidence of strong correlations between insulinaemia in the first and the second hours, if a com- plete OGTT with insulinaemias could not be performed, insulinaemia at one point should suffice. Researchers in Spain (24) also showed that higher second hour OGTT insulin levels were found in children with impaired glucose tolerance, and pointed out that it is paramount to identify young people with glucose dysregulation for the sake of early intensive intervention.

The research conducted examined carbohydrate metabolisms; fasting plasma glucose values were not significantly different in adolescents with MS using both definitions, which shows that this criterion is not good enough for diagnosing a carbohydrate metabolism disorder in children and adolescents with MS. The application of specific criteria for diagnosing MS in children and adolescents led to more patients being diagnosed with the illness, thus providing an insight into the early changes in the carbohydrate metabolism in these patients. There were statistically significant increases registered in insulinaemia levels in the first and second hours of the OGTT and HOMA IR in the adolescents with MS using both definitions. This research and the other studies have shown that the oral glucose tolerance test, HOMA IR and insulinaemia, in contrast to fasting glucose, are useful to predict glucose dysregulation in obese children and adolescents (25). Monitoring glucose and insulinaemia levels in the latest research led to the conclusion that the function of $\beta$ pancreatic cells is severely damaged in normoglycaemic people, much sooner than the development of glucose tolerance disorder and insulin resistance (26-30). Due to the statistically significant increase in insulinaemia levels in the first and second hours of the OGTT and HOMA IR in children with MS, this research confirms the need to examine further the carbohydrate metabolism in all children with MS. A study among obese children in Great Britain discovered that $46 \%$ of them 
suffered from carbohydrate metabolism disorder, $40 \%$ from hyperinsulinism, $11 \%$ from glucose tolerance disorder, while a disorder in fasting plasma glucose was registered in only $0.8 \%$ of the subjects (27). Insulin values in the second hour OGTT were significantly higher in the obese patients in this study, and it is known that there is a strong correlation between insulin resistance and elevated blood pressure, and elevated serum triglyceride was confirmed (28). Children suffering from glucose tolerance are more likely to develop cardiovascular disorders in later stages of their life (29). The increased release of free fat acids from adipocytes and the synthesis of triglycerides in the liver are the foundation for the further development of lipid disorders in MS $(30,31)$. In this study, a pathological result of the OGTT was recorded in 90\% adolescents with MS and insulin resistance/ increased insulin forms the basis of the other components of MS. Long-term observational studies have shown that children with MS are at increased risk of developing type 2 diabetes and indicators for cardiovascular disease in adulthood $(32,33)$. The results of this research show that the onset of metabolic disorder is evident in children and, bearing in mind the reversibility of glucose tolerance disorder, hyperinsulinaemia and insulin resistance, it is of vital importance to examine carbohydrate metabolism meticulously.

\section{Conclusion}

The results of the research show a significant percentage of glucose dysregulation in children with MS. We focused on the importance of screening for all components of MS and a detailed examination of the carbohydrate metabolism in obese children and adolescents. Children with MS are at increased risk of developing type 2 diabetes and cardiovascular disease in adulthood, and it is neces- sary to identify children who are at risk for the sake of future preventive strategies.

Conflict of interest: The authors declare that they have no conflict of interest.

Authors' contributions: Conception and design: IV and DK; Acquisition, analysis and interpretation of data: IV and DK; Drafting the article: IV; Revising the article critically for intellectual content: IV and DK; Approved final version of the manuscript: IV and DK.

\section{References}

1. Reaven GM. Banting lecture 1988. Role of insulin resistance in human disease. Diabetes. 1988;37:1595-607.

2. Alberti KGMM, Zimmet P, Shaw J for the IDF Epidemiology Task Force Consensus Group, The MS-a new worldwide definition. Lancet. 2005;366(9491):1059-62.

3. Zimmet P, Alberti G, Kaufman F, Tajima N. The MS in children and adolescents. Lancet. 2007;369(9579):2059-61.

4. Cook S, Weitzman M, Auinger P, Nguyen M, Dietz WH. Prevalence of a MS phenotype in adolescents: findings from the third National Health and Nutrition Examination Survey, 1988-1994. Arch Pediatr Adolesc Med. 2003;157:821-27.

5. De Ferranti SD, Gauvreau K, Ludwing DS, Newfwld EJ, Newburger JW, Rifai N. Prevalence of the MS in American adolescents: findings from the third national health and nutrition examination survey. Circulation. 2004;110:2494-7.

6. Cruz ML, Weigensberg MJ, Huang TT, Ball G, Shaibi GQ, Goran MI. The MS in overweight Hispanic youth ant the role of insulin sensitivitiy. J Clin Endocrinol Metab. 2004;89:108-13.

7. Weiss R, Dziura J, Burgert TS, Tamborlane WV, Taksali SE, Yeckel CW, et al. Obesity and the MS in children and adolecents. N Engl J Med. 2004;350:2362-74.

8. Ford ES, Ajani UA, Mokdad AH. The MS and concentrations of C-reactive protein among U.S youth. Diabetes Care. 2005;28:878-81.

9. Goodman E, Daniels S, Morrison J, Huang B, Dolan L. Contrasting prevalence of and demographic disparities in the World Health Organization and National Cholesterol Education Program Adult Treatment Panel III definitions of MS among adolescents. J Pediatr. 2004;145:445-51. 
10. Raikkonen K, Matthews KA, Salomon K. Hostility Predicts MS Risk Factors in Children and Adolescents. Health Psychol. 2003;22:279-86.

11. Alberti KGMM, Zimmet P. Definition, diagnosis and classification of diabetes mellitus and its complications. Part 1 diagnosis and classification of diabetes mellitus provisional report of a WHO consultation. Diabet Med. 1998;15:539-53.

12. Balkau B, Charles MA. Comment on the provisional report from the WHO consultation. European Group for the Study of Insulin Resistance (EGIR). Diabet Med. 1999;16:442-3.

13. Ma R, Chan J. Metabolic Complications of Obesity:An overview. In:Williams G, Frühbeck G, editors. Obesity: Science to Practice. Oxford: Wiley-Blackwell; 2009. p. 237-61.

14. Inge TH, Garsia V, Daniels S, LangfordL, Kirk S, Roehrig $\mathrm{H}$, et al. A multidisciplinary approach to the adolescent bariatric surgical patient. J Pediatr Surg. 2004;39:442-7.

15. The Forth Report on the Diagnosis, Evaluation, and Treatment of High Blood Pressure in Children and Adolescents. Pediatrics. 2004;114:555-76.

16. American Diabetes Association. Diagnosis and classification of diabetes mellitus. Diabetes Care. 2004;27:5-10.

17. Heinze E, Holl RW. Test of $\beta$-Cell function in childhood and adolescence: An overview. In: Ranke MB, editor. Diagnostics of Endocrine Function in Children and Adolescents. Basel: Karger; 2003. p. 318-38.

18. Matthews DR, Hosker JP, Rudenski AS, Naylor BA, Treacher DF,Turner RC. Homeostasis model assessment: insulin resistanceand $\beta$-cell function from fasting plasma glucose and insulinconcentrations in man. Diabetologia. 1985;28:412-19.

19. CDC. National Center For Health Statistics (NCHS) Growth Chartin collaboration with the National Center for Chronic Disease Prevention and Health Promotion. 2002 [cited 2003 Aug 15]; Available from: http://www.cdc.gov/growthcharts.

20. Fernández JR, Redden DT, Pietrobelli A, Allison DB. Waist circumference percentiles in nationally representative samples of African-American, European-American, and Mexican-American children and adolescents. J Pediatr. 2004;145(4):439-44.

21. Nicholson JF, Pesce MA. Reference ranges for laboratory tests and procedures; An overview. In: Behrman RE, Kliegman RM, Jenson HB, editors.
Nelson Textbook of Pediatric 17th. Philadelphia: Saunders; 2003. p. 2396-426.

22. Invitti CMC, Gilardini L, Pontiggia B, Mazzilli G, Morabito F, Viberti C. Prevalence of MS in obese children. Diabetes. 2003;52:A70.

23. Singh R, Shaw J, Zimmet P. Epidemiology of childhood type 2 diabetes in the developing world. Pediatric Diabetes. 2004;5:154-68.

24. Bahíllo-Curieses MP, Hermoso-Lopez F, Martínez-Sopena MJ, Cobreros-García P, García-Saseta P, Tríguez-García M, et al. Prevalence of insulin resistance and impaired glucose tolerance in a sample of obese Spanish children and adolescents.Endocrine. 2012;41(2):289-95.

25. Hirschler V, Calcagno M, Aranda C, Maccallini G, Jadzinsky M. Can the MS identify children with insulin resistance? PediatrDiab. 2007;(5):2727.

26. Ghergherechi R, Tabrizi A. Prevalence of impaired glucose tolerance and insulin resistance among obese children and adolescents. Ther Clin Risk Manag. 2010;6:345-49.

27. Viner RM, Segal TY, Lichtarowicz-Krynska E, Hindmarsh P. Prevalence of the insulin resistance syndrome in obesity. Arch Dis Child Childhood. 2005;90:10-4.

28. Caceres M, Teran CG, Rodriguez S, Medina M. Prevalence of insulin resistance and its association with MS criteria among Bolivian children and adolescents with obesity. BMC Pediatr. 2008;8:31.

29. Reinehr T, Wunsch R, de Sousa G, Toschke AM. Relationship between MS definitions for children and adolescents and intima-media thickness. Atherosclerosis. 2008;199(1):193-200.

30. Della Corte C, Nobili V. Pediatric non-alcoholic fatty liver disease: A growing problem. Pediatrics Today. 2015;11:81-4.

31. Fitzpatrick E, Hadzic N. Paediatric non-alcoholic fatty liver disease: An emerging threat. Pediatrics Today. 2015;11:1-9.

32. Magge SN, Goodman E, Armstrong SC. The MS in Children and Adolescents: Shifting the Focus to Cardiometabolic Risk Factor Clustering. Pediatrics. 2017;(140):e1-12.

33. Magnussen CG, Fraser BJ, Raitakari OT. Pediatric MS: Long-Term Risks for Type 2 Diabetes and Cardiovascular Disease.Pediatric Obesity. 2017;511-26. 